\title{
Estado e campesinato brasileiro: um panorama sobre as relações dos governos federais e as políticas públicas para o campo ${ }^{1}$
}

\author{
Brazilian state and peasantry: a perspective between the federal governments and the public \\ policies for the countryside
}

\author{
Vanessa Cristhina Zorek Daniel ${ }^{2}$ \\ Maria Tarcisa Silva Bega ${ }^{3}$
}

\begin{abstract}
Resumo
O objetivo do trabalho consiste em identificar as políticas sociais direcionadas aos trabalhadores do campo e agricultores familiares no Brasil, observando as políticas desenvolvidas nos governos eleitos democraticamente após o período de governos militares (1964-1985) - que compreende do governo de Fernando Collor de Mello até o governo de Michel Temer. Levou-se em consideração que os camponeses compõem um grupo social que foi excluído, direta ou indiretamente ao longo da história brasileira, dos direitos sociais, civis, políticos e do acesso à propriedade. As classes camponesas ansiaram por mudanças e avanços no processo de reforma agrária e assistência do Estado aos trabalhadores rurais, principalmente com a chegada dos governos democráticos. No entanto, o que se observou é que não houve mudanças estruturais na posse da terra no Brasil durante esse período. Em relação às políticas públicas, durante os anos de 1990 houve uma diminuição dos recursos para as políticas de intervenção na área da agricultura, gerando um déficit nas políticas específicas para os produtores e trabalhadores rurais, que foram substituídas por ações assistencialistas e localizadas. A partir da segunda metade dos anos 2000, as políticas direcionadas aos camponeses foram ampliadas, a exemplo de políticas que fomentam recursos para o desenvolvimento de estruturas básicas no campo, cursos, assistência técnica e políticas que auxiliam os pequenos produtores a ter acesso ao mercado. A partir de 2016 nota-se um retrocesso considerável nas políticas públicas para ao campo, através de reduções executadas e outras previstas nos orçamentos direcionados ao campo e aos produtores e trabalhadores rurais.
\end{abstract}

Palavras-chave: Camponeses. Políticas públicas. Agricultura familiar.

\begin{abstract}
This paper aims to identify social policies directed to rural workers and family farmers in Brazil, observing the policies developed on democratically elected governments, after the period of the military regime (1964-1985) - from the Government of Fernando Collor de Mello to the current Government of Michel Temer. We considered that peasants are part of a social group that has been excluded directly or indirectly throughout Brazilian history from social, civil and political rights, and from access to property. The peasant classes looked forward for changes and advances on the process of agrarian reform and State assistance to rural workers, mainly with the emergence of the democratic governments. However, we observed that there were not structural changes in land tenure in Brazil during this term. In relation to the public policies, during the 1990s, there was a

\footnotetext{
${ }^{1}$ O presente trabalho foi realizado com apoio da Coordenação de Aperfeiçoamento de Pessoal de Nível Superior Brasil (CAPES) - Código de Financiamento 001.

2 Doutoranda em Sociologia pela Universidade Federal do Paraná (UFPR). E-mail: vanessazorek@gmail.com

3 Pós-doutora em Sociologia pelo Instituto de Ciências Sociais da Universidade de Lisboa. Professora Associada da Universidade Federal do Paraná (UFPR). E-mail: tarcisa.silva@gmail.com
} 
decrease in resources for intervention policies in the agriculture sector, which generated a deficit in the specific policies for producers and rural workers. These policies were replaced by assistance and localized actions. Since the second half of the 2000s, the policies directed to peasants have been expanded, such as policies that provide resources for the development of basic rural structures, courses, technical assistance, and policies that help small farmers gain access to market. From 2016 onwards, there has been a considerable setback on public policies directed to the rural area, through reductions implemented and others foreseen in the budget directed to the rural area, producers and rural workers.

Keywords: Peasants. Public policies. Family farming.

\section{Introdução}

O conceito campesinato existe em oposição ao latifundiário, logo, quando se faz referência ao camponês, se alude às populações com poucos recursos materiais que vivem e trabalham no campo e estiveram sempre ligadas, de forma subordinada, ao latifúndio. No caso brasileiro, os camponeses, ao longo da história, foram os grupos mais excluídos dos direitos sociais, civis, políticos e do acesso à propriedade da terra. A formação da classe camponesa está ligada às desigualdades históricas, sendo tanto descendentes dos homens livres pobres quanto de escravos, mestiços e de quilombolas: são os principais prejudicados em detrimento dos benefícios concedidos à elite colonial e aos seus descendentes.

Martins (1981) aponta que durante o período colonial todos os que fossem filhos naturais, mestiços ou que não possuíssem "sangue limpo" eram interditados do direito de herança. Além disso, as heranças seguiam o regime do morgadio ${ }^{4}$, que definia o filho primogênito como herdeiro legal, o que tornava os outros herdeiros dependentes ou agregados. Entre os agregados que formam parte do campesinato brasileiro, além dos excluídos do direito da herança, estavam os índios e mestiços. Os agregados não tinham direito de propriedade, mas tinham como obrigação pagar tributos, serviços e gêneros conforme as condições e circunstâncias dos fazendeiros. O morgadio possibilitou a concentração da riqueza através da herança; contudo, mantinha a possibilidade da abertura de novas fazendas e propriedades através do uso da terra. Esse processo é conhecido como sesmarias, em que para se tornar um sesmeiro, o ocupante deveria abrir a fazenda e tornar a terra útil para pedir a concessão. No entanto, as terras improdutivas poderiam ser redistribuídas a outro sesmeiro, pois o fazendeiro concedia o benefício do uso da terra e não as terras.

\footnotetext{
${ }^{4} \mathrm{O}$ morgadio teve fím em 1835, apontado como causa do empobrecimento da população, como também de muitos conflitos familiares (MARTINS, 1981).
} 
Entre a grande parcela dos excluídos que se formou durante o período colonial está o branco deserdado pelo morgadio, mas que tinha o direito de abrir e obter sua sesmaria. O mestiço pobre poderia abrir uma posse, mas por não ter "sangue puro" não poderia se tornar um sesmeiro. Entre os que compunham o campesinato dessa época estavam os agregados, os posseiros e os sitiantes. $\mathrm{O}$ posseiro tinha a posse da terra, mas não o seu domínio; o sitiante era dono de um pequeno pedaço de terra, não de uma sesmaria. Já os agregados e moradores de favor eram vistos como sitiantes (MARTINS, 1981).

Os camponeses, como lembra Martins (1981), além de excluídos da dinâmica econômica colonial, também foram excluídos da estrutura de poder. Na Constituição de 1824, ficou estabelecido que os direitos políticos (de votar e ser votado) eram concedidos aos homens com uma renda mínima, entre cem e quatrocentos mil réis, dependendo da modalidade de eleições: os eleitores de paróquia que elegiam os eleitores regionais, os quais poderiam votar nos senadores e deputados, deveriam apresentar uma renda mínima de cem mil réis, assim como poderiam ser considerados eleitores regionais os que possuíssem uma renda maior que duzentos mil réis, e as eleições gerais eram restritas aos que possuíssem mais de quatrocentos mil réis de renda anual. Já os libertos não possuíam nenhum direito político. Quando o Brasil se tornou República os camponeses continuaram à margem em relação aos direitos civis, uma vez que a Constituição de 1891, embora tenha eliminado a restrição de renda mínima, manteve o impedimento do voto dos analfabetos.

Wanderley (1996) aponta que o campesinato brasileiro é reflexo dos processos sociais que a história da agricultura brasileira percorreu, isto é, estruturas marcadas pela dominação social, econômica e política representadas pelos latifúndios e associadas à escravidão. As grandes propriedades de terra não apenas sempre estiveram presentes na história brasileira como principalmente foram os tipos de propriedades que receberam estímulos do Estado. A história do campesinato no Brasil pode ser descrita como uma história de lutas em busca de um espaço na sociedade e na economia. Os obstáculos encontrados pelos camponeses estão relacionados a essa estrutura, o que inviabiliza a possibilidade de desenvolver potencialidades do seu sistema de produção e da vida social.

O sistema político brasileiro manteve ao longo de sua história privilégios para as classes dominantes, em detrimento da classe trabalhadora. Entre os governos oligárquicos, as ditaduras e mesmo nos governos democráticos, principalmente durante o século XX, o Estado dificultou a formação das organizações políticas e sociais populares. A título de exemplo, submeteu à sua tutela os sindicatos dos trabalhadores urbanos e rurais. 
Apesar disso, no Brasil da década de 1980 se desenvolveu um forte movimento popular em prol da reforma agrária: o Movimento dos Trabalhadores sem Terra (MST). Nos anos de 1990 o MST se configurava como o maior movimento da América Latina (CARTER, 2010). No entanto, os primeiros movimentos relacionados à reforma agrária no Brasil surgiram ainda na década de 1950 , na região Nordeste, com mobilizações que ganharam mais força na década de 1960. Mas essas lutas sofreram um grande revés após o golpe militar em 1964, que inviabilizou o decreto promulgado em 13 de março de 1964 pelo presidente João Goulart (OLIVEIRA, 2001), que declarava de interesse social, para fins de reforma agrária

as áreas rurais que ladeiam os eixos rodoviários federais, os leitos das ferrovias nacionais, e as terras beneficiadas ou recuperadas por investimentos exclusivos da União em obras de irrigação, drenagem e açudagem, atualmente inexploradas ou exploradas contrariamente à função social da propriedade, e dá outras providências (BRASIL, 1964).

Nos primeiros meses do regime militar foi anunciada uma lei de reforma agrária que tinha como principal objetivo promover a colonização na Amazônia. Com essa lei os defensores da reforma agrária, principalmente a Confederação Nacional dos Trabalhadores na Agricultura (Contag), criaram uma grande rede de sindicatos rurais. Mesmo sob um regime militar, esses sindicatos funcionaram como um meio importante para a formação da identidade camponesa, como também um espaço para a formação política e social e a promoção de debates envolvendo os problemas agrários (OLIVEIRA, 2001).

Durante o período de governos autoritários, houve políticas dispostas a promover a chamada modernização da agricultura, que transformou empresários capitalistas em proprietários de enormes extensões de terra. Essa política contou com incentivos fiscais da Superintendência do Desenvolvimento do Nordeste (Sudene) e Superintendência do Desenvolvimento da Amazônia (Sudam). Os capitalistas urbanos passaram a ser grandes proprietários de terras no Brasil. Dessa forma, essa aliança solidificou ainda mais a terra como propriedade, como foi observado por Martins:

O monopólio de classe sobre a terra assegura ao capitalista o direito de cobrar da sociedade inteira um tributo pelo uso da terra. É a chamada renda fundiária ou renda da terra. A renda não existe apenas quando a terra é alugada; ela existe também quando a terra é vendida. Alugar ou vender significa cobrar uma renda para que a terra seja utilizada. [...] A terra é completamente diferente dos outros meios de produção. A apropriação de uma máquina pelo capitalista e, através dela, do trabalho do operário, pode parecer legitima na medida em que, tendo os trabalhadores que a produziram trabalhado sob tutela do capital, mediante o salário, o resultado do seu trabalho aparece como produto do capital. O mesmo não acontece com a terra. Já constatavam os economistas clássicos dos séculos XVIII e XIX 
que a propriedade capitalista da terra é uma irracionalidade porque a terra não é produto do trabalho e, por isso mesmo, não pode ser produto do capital (MARTINS, 1980, p. 60-61).

As grandes frações de terra atualmente pertencem aos grandes grupos econômicos, por servirem tanto como reserva de valor quanto como reserva patrimonial. Esses grupos usam a posse de grandes extensões de terra como garantia de acesso aos financiamentos bancários e às políticas de incentivos governamentais (OLIVEIRA, 2001).

Os apoiadores do projeto de modernização da agricultura e os militares que ocuparam o governo na ditadura militar defendiam a modernização tecnológica da agricultura e, a partir dessa postura, os ajustes no setor da agricultura e na industrialização da economia passaram a ser realizados através de ações e políticas públicas. As ações eram entendidas como:

crédito rural, garantia de preços mínimos, seguro agrícola, pesquisa agropecuária, assistência técnica e extensão rural, incentivos fiscais às exportações, minidesvalorizações cambiais, subsídios à aquisição de insumos, expansão da fronteira agrícola, e o desenvolvimento de infraestruturas. Por cerca de 20 anos, este foi o referencial setorial predominante que orientou as ações do Estado no setor agrícola e pecuário (GRISA; SCHNEIDER, 2015, p. 129).

Grisa e Schneider (2015) ainda acrescentam que essas políticas tinham um caráter muito seletivo e beneficiava, em especial, médios e grandes agricultores localizados no Sul e Sudeste e os que produziam principalmente produtos para exportação ou de interesse da agroindústria. Esses autores também salientam que, durante as duas décadas da ditadura militar, a sociedade civil aliada à agricultura familiar não encontrou espaço para diálogo com os gestores públicos. O contexto político não permitiu a participação dessa categoria de atores e ainda impôs limites às ações críticas e propositivas da Contag, principalmente as que envolviam os pequenos produtores. Desse modo, as principais políticas públicas foram direcionadas para a modernização da agricultura, o que não envolvia a agricultura familiar.

A lógica capitalista facilitou a concentração da terra e isso levou, e ainda leva, cada vez mais pessoas para as áreas urbanas, gerando desemprego, pobreza e fome. Alguns dados sobre os estabelecimentos agropecuários com até 100 hectares mostram que estes estão em constante diminuição. O Censo Agropecuário de 1985 mostrou que existiam cerca de 5.252.265 propriedades no Brasil de até 100 hectares; no Censo de 1995-96 somavam-se 4.318.861. Isso se deve tanto à crise agrária na década de 1990 quanto à mudança de conduta dos donos de terras. Pois, ao ser verificada a condição dos produtores que estavam dentro dessa margem de queda, foi percebido que mais de $87 \%$ eram arrendatários, parceiros e posseiros. Isso mostra que com a luta social pela 
reforma agrária, os proprietários preferiram não mais ceder suas terras aos arrendatários, parceiros ou posseiros, o que acabou intensificando ainda mais a migração do campo para a cidade. A exclusão do campo acontece também com muitos filhos de camponeses que possuem pequenas propriedades de até dez hectares e que não poderão se tornar camponeses nas terras de seus pais, dada a incapacidade de parcelamento delas. Assim, possuem duas alternativas: irem para a cidade ou entrarem na luta pela reconquista da terra (OLIVEIRA, 2001). Esse contexto aponta para a importância das políticas públicas direcionadas aos camponeses e produtores familiares, como auxílio na preservação dos modos de vida rural, na garantia de renda e consequentemente na manutenção da posse da terra pelos pequenos produtores.

\section{O Estado brasileiro, o campesinato e as políticas para o campo no período pós-redemocratização}

Na década de 1980 a sociedade brasileira passou por mudanças políticas importantes, como a abertura democrática e a promulgação da Nova Constituição em 1988. Nessa década também ocorreu a consolidação do sindicalismo rural através do Contag e o surgimento do Movimento dos Trabalhadores Rurais sem Terra (MST), que se uniram em torno de uma nova concepção de desenvolvimento rural (WANDERLEY, 2014).

Na década de 1990 houve alta expectativa em relação à reforma agrária dentro dos movimentos sociais. No entanto, com a adoção do neoliberalismo como modelo econômico, foram definidas, para os governos eleitos, novas agendas de ação como: redução da intervenção do Estado, privatização de empresas estatais, desregulamentação da economia e a liberalização dos mercados. Cumprindo o receituário neoliberal, tal diminuição da intervenção do Estado na área da agricultura resultou na diminuição de recursos direcionados às políticas agrícolas e políticas de formação de estoques reguladores, das tarifas de importação de produtos alimentares e do algodão.

Em relação à reforma agrária, o governo Collor - primeiro governo eleito depois da ditadura militar - não praticou a desapropriação de terras prevista na Constituição, realizando apenas assentamentos a partir da aquisição por compra e venda de terras (CUNHA FILHO, 2007). Entre os governos de Collor (1990-1992) e Itamar Franco (1992-1994), as políticas de reforma agrária foram ínfimas, somadas à imensa repressão dos movimentos sociais de luta pela terra. Nesse período houve um total de 504 ocupações feitas por 80 mil famílias e o Governo Federal assentou 62.799 famílias (ROCHA, 2009). 
Durante esse período ocorre abertura comercial e extinção de subsídios e controle de preços (JANK et al., 2005). Ao longo dos anos 1990 houve uma diminuição dos gastos federais direcionados à agricultura. Em comparação ao início dos anos 1980, por exemplo, os gastos do orçamento federal destinados à agricultura eram de 5,75\%; entre 1995-1999 estiveram em 2,11\%, o que corresponde à diminuição de créditos agrícolas, preços mínimos e estoques reguladores. $\mathrm{O}$ Estado passou a promover políticas públicas compensatórias pontuais e regionais, com prioridade em políticas socias que visavam suavizar a condição da pobreza extrema com programas de transferência de renda, a exemplo do Programa Bolsa Escola, com objetivo de evitar a evasão escolar de crianças e adolescente em vulnerabilidade social, e o Programa Bolsa Alimentação, que previa a complementação da renda para mães gestantes, amamentando e com crianças entre seis meses a seis anos de idade.

Contudo, a diminuição dos recursos públicos não afetou a agricultura empresarial voltada para a exportação, que continuou apresentado resultados positivos, mas prejudicou a agricultura familiar e, consequentemente, influenciou na queda de renda de parte dos pequenos agricultores. Os dados do IBGE de 1996 apontam que "aproximadamente 20,4\% dos produtores agrícolas tinham rendas negativas e 59,5\% abaixo da renda mediana, o que quer dizer que se tratava de agricultores eminentemente pobres" (BELIK et al., 2001, p. 123).

No governo de Fernando Henrique Cardoso (1995-2002), a agenda da reforma agrária foi adotada por conta das pressões dos movimentos sociais e intelectuais. A postura dos movimentos sociais nesse contexto é bastante propositiva (COELHO, 2016). Os camponeses passaram a exigir não só políticas específicas, mas a participação na construção dessas. Em resposta, houve a construção do documento "Propostas e recomendações de política agrícola diferenciada para o pequeno produtor rural", desenvolvida por uma Comissão Técnica do Pequeno Produtor, no Ministério da Agricultura, do Abastecimento e da Reforma Agrária. O documento apresentava propostas como a criação de um programa especial de crédito para pequenos produtores, com prazos, carências e formas de pagamentos diferenciados, como também a criação de um seguro agrícola e um programa social que fizessem frente ao Mercosul, direcionados ao pequeno produtor (GRISA; SCHNEIDER, 2015).

Diante de um cenário de mobilizações sociais e da presença de um novo paradigma nos estudos rurais, mostrando a importância da agricultura familiar, o Governo Federal criou a primeira política agrícola nacional, o Programa Nacional de Fortalecimento da Agricultura Familiar (Pronaf), direcionado especificamente para o pequeno agricultor. O Pronaf, criado em 1995, é caracterizado 
como uma política de crédito rural que possibilitaria o acesso dos agricultores familiares ao mercado. Esse programa marca o início da construção de algumas medidas direcionadas ao fortalecimento da produção agrícola dos produtores familiares, como a criação do seguro da agricultura alimentar (GRISA; SCHNEIDER, 2015).

Trágicos acontecimentos ocorreram, como os massacres de Corumbiara, em Rondônia - que ocorreu em 9 de agosto de 1995 - quando, em uma ação de reintegração de posse, policiais militares e pistoleiros entraram em confronto com trabalhadores sem-terra acampados na Fazenda Santa Elina, resultando em 12 mortes e 64 feridos; e o massacre de Eldorado dos Carajás, no Pará em 17 de abril de 1996 - , quando por ordem do então governador Almir Gabriel a Polícia Militar do Pará, com a intenção de liberar a rodovia PA-150, caminho utilizado na marcha de protesto pelos trabalhadores sem-terra contra a demora na desapropriação de terras, culminou no assassinato de 21 trabalhadores rurais. Uma semana após o massacre de Eldorado dos Carajás foi anunciada a criação do Ministério da Reforma Agrária, passando algumas questões relacionadas à reforma agrária a ser incluídas na pauta do governo federal. Em 1996 foi criado o Gabinete Extraordinário de Política Fundiária, depois transformado no Ministério do Desenvolvimento Agrário (MDA).

O governo de Fernando Henrique Cardoso (1995-2002), do Partido da Social Democracia Brasileira (PSDB), priorizou a abertura e a busca da estabilidade econômica, o que sem dúvida, trouxe benefícios para os grandes proprietários rurais, com modelo de produção agrícola conhecido como "agronegócio", o qual se desenvolveu de forma intensa ao longo da década de 1990 através de corporações nacionais e transnacionais. Com o favorecimento desse modelo pelo Estado, o Brasil acabou por criar ainda mais obstáculos para os pequenos produtores, já que o agronegócio visa um desenvolvimento particular, sem contribuição com a promoção social, sendo restrito aos interesses de pequenos grupos, mas muito ricos (COELHO, 2016).

No primeiro mandato de FHC (1995-1998), o Executivo buscou evitar os conflitos pela terra, assentando famílias já acampadas, sem, contudo, alterar a estrutura fundiária brasileira. O segundo mandato (1999-2002) foi marcado pela "reforma agrária de mercado", gerando sérias críticas dos movimentos sociais e organizações do campo. A reforma agrária de mercado foi uma política de governo que buscava possibilitar a compra de terras por pequenos trabalhadores rurais (COELHO, 2016).

Rocha (2009) aponta que entre 1995 e 1998 houve um contingente de 287 mil famílias de trabalhadores rurais que participaram de ocupações como ação política de luta pela terra e destas o governo assentou 245.408 famílias em 2.251 assentamentos. No segundo governo, o número de 
famílias que participaram desses modelos de ação foi de 148 mil. Tal diminuição na participação se deu principalmente pelo cumprimento da Medida Provisória 2109-52, expedida em 24 de maio de 2001, que criminaliza as ações de ocupação, condicionando também as áreas ocupadas a um hiato de dois anos para a desapropriação e, em caso de reincidência, de quatro anos (BRASIL, 2001). Com a diminuição das ocupações e sendo estas a principal forma de ação dos movimentos que reivindicam a reforma agrária, houve também uma diminuição das ações das famílias ligadas aos movimentos rurais. Entre 1999 e 2002 percebe-se uma diminuição no número de assentados: foram 148.323 famílias em 1.673 assentamentos (ROCHA, 2009, p. 48-49).

O modelo neoliberal, com a diminuição de recursos do Estado, influenciou na maneira de se fazer políticas públicas. É perceptível, a partir de 1997, a ênfase em políticas públicas com foco em ações sociais e assistências localizadas como o Programa Comunidade Solidária iniciado no governo FHC e aperfeiçoado nos governos Lula e Dilma por meio do Programa Fome Zero, que se propunha a realizar ações relacionadas à questão alimentar, à miséria e à pobreza, visando à diminuição da mortalidade infantil, o acesso à alimentação, à educação básica, ao fortalecimento da agricultura familiar, saneamento, qualificação profissional, entre outros. Como sua atuação concentra-se em áreas de maior pobreza, atinge muitas áreas rurais.

Entre os anos de 1998 e 2000, surgiram várias ações de transferência de renda, favorecendo inúmeros agricultores de baixa renda, como o Bolsa Escola, Bolsa Alimentação e Auxílio Gás, que em 2003 passou a compor o Programa Bolsa Família (GRISA; SCHNEIDER, 2015). Essas políticas não foram pensadas exclusivamente para os agricultores, mas foram ações que pretendiam solucionar problemas relacionados à fome e à miséria, sem definitivamente traçar propostas para solucionar a questão agrária.

Em 1998 foi criado o Banco da Terra, que visava ao financiamento de propriedades rurais para trabalhadores rurais não proprietários. Os movimentos que lutam pela reforma agrária percebiam-no como uma forma de transformar a luta social em oportunidade de negócios. Já o governo argumentava que as novas propostas para a "reforma agrária" seriam uma forma de fazê-la sem conflitos. Entre os programas lançados pelo governo FHC está o "Novo Mundo Rural”, no qual considerava os pequenos produtores como empreendedores que deveriam buscar um modelo de produção competitiva (COELHO, 2016). Esse e outros programas ignoraram o modelo histórico herdado das comunidades rurais, em que a vida no campo não carrega a gênese competitiva do mercado. Os assentamentos eram vistos pelo governo apenas como um meio de subsistência e renda, e não como um espaço social, cultural e um modo de vida. 
Outro programa, “Acesso Direto à Terra”, previa a inscrição ao programa, via Correios, dos trabalhadores rurais. Assim, não era necessário que o trabalhador se unisse aos movimentos sociais, mas que aguardasse em sua casa a resposta do Executivo. O projeto ficou conhecido como uma propaganda enganosa com objetivo de enfraquecer os movimentos sociais que defendiam a reforma agrária. Outro programa foi o "Cédula da Terra". Para participar desse programa era necessário que os produtores rurais buscassem um agente financeiro para apresentar a proposta de um assentamento. O projeto, depois de analisado e com orçamento definido, seria avaliado pelos órgãos estatais e, se aprovado, receberia uma carta de crédito para associação e por meio de um agente estatal seria feita a compra da terra (LEITE; MEDEIROS, 2004, p. 366-367).

De modo geral, os governos FHC tiveram como principal objetivo inserir os planos de reforma agrária na lógica do mercado. A reforma agrária de mercado logrou ao enfraquecer e criar desconfiança da sociedade em relação aos movimentos sociais, fazendo com que eles fossem vistos como inimigos da sociedade e da modernização e que buscam meios "fáceis" e "ilegítimos" para obter terra. Essas políticas colocam o Estado e o Mercado como formadores e fornecedores de oportunidades. Desse modo, o trabalhador sem-terra ou o pequeno produtor receberiam oportunidades do governo e, consequentemente, deveriam se encaixar em algum dos programas. Todavia, o seu insucesso ou sua inadequação corresponderiam a uma falta de "interesse" para com as soluções oferecidas.

Em síntese, as políticas públicas nos governos FHC direcionadas ao campesinato foram políticas mínimas, pensadas como uma forma de minimizar os conflitos e protestos sociais, diminuir de maneira localizada a miséria a partir de programas de transferência de renda. Em relação à apresentação dos projetos para o campo, não tiveram como beneficiário o trabalhador rural, mas uma espécie de "marketing" político, apontando "soluções mercadológicas", deslegitimando as pautas dos movimentos de luta pela terra, isso porque defendiam que, através do mercado (compra da terra) "a questão da terra" seria resolvida, sobretudo sem violência.

A vitória eleitoral de Luiz Inácio Lula da Silva (2003-2006; 2007-2010), eleito pelo Partido dos Trabalhadores (PT), foi recebida como símbolo de esperança pelos movimentos sociais, principalmente pelo MST. Lula se elege com uma plataforma muito mais popular e progressista em relação ao governo que sucede. No primeiro ano de governo é lançado o II Plano Nacional da Reforma Agrária. O II PNRA é, até então, o maior plano de reforma agrária do Brasil e teve por meta o assentamento de 400.000 famílias no período entre 2003-2006 e a regularização de 100.000 propriedades. Entre 2003 e dezembro de 2004 o governo federal assentou 117.555 famílias, 
chegando a $81 \%$ da sua meta para esse período, que era de 145 mil famílias assentadas. Além dos assentamentos, o governo Lula atendeu mais de 300 mil famílias já assentadas com serviços de assistência técnica e ampliação dos projetos que visavam garantir não só a distribuição de terra, como também a qualidade no processo de reforma agrária. Nessa direção houve um aumento do investimento nas famílias já assentadas, de R\$ 7.700,00 em 2003 para R\$ 16.000,00 em 2004. Envolveu processos de melhoria em projetos de produção e assistência técnica e a construção de infraestrutura básica necessária para a dignidade humana, como cisternas, moradias e a preservação ambiental. Contudo, os resultados apresentados pelo primeiro governo Lula ficaram aquém das expectativas dos movimentos sociais de luta pela terra (ESQUERDO; BERGAMASCO, 2013).

Em 2005, o governo Lula assentou 127 mil famílias. A maioria dos assentados não foram colocados em terras desapropriadas por interesse social e sim em assentamentos já existentes ou em terras públicas. Havia, aqui, um indicativo de que o então governo não pretendia mudar a lógica de atuação na política de reforma agrária (ESQUERDO; BERGAMASCO, 2013). O governo Lula, no entanto, não teve a mesma postura em relação aos movimentos sociais de luta pela terra que o governo antecessor, pois não houve uma relação de criminalização para com esses movimentos.

O primeiro governo Lula teve como principais metas a geração de empregos e o combate à pobreza. Assim, as políticas agrárias desenvolvidas visavam à segurança alimentar, ao fim da fome e à garantia de uma renda mínima, e não a uma mudança das estruturas sociais e agrárias. No segundo governo Lula (2007-2010) o número de famílias assentadas foi menor do que no primeiro mandato, sendo um período marcado pela ausência de novos planos e metas para a reforma agrária.

Entre os anos de 2003 e 2005 houve um crescimento na criação de assentamentos de reforma agrária em comparação aos governos FHC. Contudo, após o segundo mandato de Lula e nos governos de Dilma Rousseff, também do PT (2011-2014; 2015-2016), os números caem. Cabe lembrar que Dilma recebeu indicação e apoio de Lula em suas candidaturas presidenciais e havia ocupado, em seu governo, os cargos de ministra-chefe da Casa Civil e ministra de Minas e Energia. O enfoque das políticas públicas para o trabalhador rural nos governos petistas não foi direcionado à distribuição de terras, mas sim à assistência aos assentamentos existentes e aos projetos de melhorarias de infraestrutura e de produção.

Tanto o governo de Lula como de Dilma tiveram sua principal contribuição para a agricultura campesina e familiar relacionada aos programas contra a fome e a segurança alimentar e nutricional. Pois, a partir disso, se institucionalizaram políticas que possibilitaram a entrada de 
produtores familiares no mercado (GRISA; SCHNEIDER, 2015), melhorando a renda das famílias produtoras, proporcionando qualidade de vida e possibilidade de investimentos nas propriedades.

Um dos programas foi o Projeto de Aquisição de Alimentos (PAA), criado em 2003. Esse projeto estimulava a compra de produtos da agricultura familiar, ao mesmo tempo em que pensava ações de segurança alimentar para a população em condição de vulnerabilidade social. O programa ganhou maior força em 2009, quando o Programa Nacional de Alimentação Escolar (PNAE) e a Lei 11.947 determinaram que pelo menos $30 \%$ dos alimentos comprados para alimentação escolar com recursos federais fossem oriundos da produção de alimentos da categoria social. Em 2012 foi ampliada a possibilidade de mercado para os produtos da agricultura familiar, através de uma ação que permite aos órgãos públicos do Executivo a compra direta e indireta de alimentos da agricultura familiar por meio de chamadas públicas (GRISA; SCHNEIDER, 2015).

Outro programa importante a ser mencionado é a Política de Garantia de Preços Mínimos (PGPM) para os Produtos da Sociobiodiversidade, criado em 2008 e que garante, em caso de uma venda abaixo do preço fixado pelo Governo Federal, um bônus. Esse programa não trata da compra desses produtos, mas de um repasse financeiro aos extrativistas com o objetivo de atingir o preço mínimo de comercialização. Além desses projetos, nos governos petistas foram feitos investimentos na área de infraestrutura e crédito, como também a criação de selos especiais, como o selo da Participação da Agricultura Familiar e o Selo Quilombos do Brasil, das indicações geográficas e certificações de produtos orgânicos (GRISA; SCHNEIDER, 2015).

Os governos Lula, em conjunto com os governos Dilma Rousseff, proporcionaram a ampliação do alcance de programas sociais e o aumento real do salário mínimo. Todavia, é importante destacar que as políticas governamentais voltadas para a agricultura não atingiram apenas os grupos mais vulneráveis, mas também setores do agronegócio. Como exemplo tem-se os financiamentos de fusões e da internacionalização de corporações nacionais de alimentos e agrocombustíveis, originários principalmente do agronegócio. Dessa forma, as políticas dos governos petistas investiram consideravelmente não só no latifúndio, mas na sua ampliação (CUNHA, 2016).

Já no primeiro governo Dilma ficou evidente que apesar das políticas públicas efetivas para o setor da agricultura familiar e camponesa e o diálogo com os movimentos de luta pela terra, não haveria mudanças na estrutura fundiária brasileira. Isso não destoa do modelo democrático atual, posto que as democracias contemporâneas possuem poucas chances de fazer uma reforma agrária 
revolucionária, pois é seu pressuposto a garantia dos direitos constitucionais do Estado de Direito (CARTER, 2010).

O segundo mandato de Dilma Rousseff (2015-2016) se inicia em um contexto político conturbado, com as alianças políticas fragilizadas e com investigações contra o governo e empresas financiadas com dinheiro do Banco Nacional do Desenvolvimento Econômico e Social (BNDES). São várias acusações de corrupção envolvendo membros do Executivo e o Legislativo Federal, criando grande revolta popular contra o governo Dilma, contexto que contribuiu para a conformidade popular com o processo de impeachment contra ela.

O segundo mandato de Dilma evidenciou formas contraditórias de gestão, numa tentativa de manter alianças políticas e proteger o mandato presidencial. Desse modo, ao mesmo tempo em que a presidenta defendia os direitos trabalhistas e os programas sociais, aceitou uma agenda neoliberal ortodoxa. No fim de 2015, atendendo a uma grande pressão política, anuncia um corte no orçamento de 26 bilhões de reais. Entretanto, essa, entre outras medidas, não foi capaz de garantir o apoio do Congresso Nacional ao seu mandato. Em maio de 2016, a votação na Câmara dos Deputados registra o resultado de 367 a favor do processo de impeachment e 137 contra. Em seguida, Dilma é substituída por seu vice-presidente, Michel Temer (PAULA et al., 2017).

Michel Temer (2016-2018) assume o cargo presidencial com o apoio de alianças políticas que objetivaram formas constitucionais para interromper o mandato de Dilma Rousseff. Já em suas primeiras declarações, apresenta um projeto de governo pautado em uma visão econômica neoliberal ortodoxa, modelo que perdeu nas urnas em 2014. Ainda que os governos de Lula e Dilma não tenham fugido ao modelo econômico neoliberal, foram gestões que buscaram conter o processo de enfraquecimento do Estado, melhorando alguns aspectos do sistema de educação e o nível da vida da população, principalmente da camada mais pobre, desenvolvendo "políticas sistemáticas de distribuição de renda" (SADER, 2009, p. 84).

Com o impeachment de Dilma Rousseff foi implantado um projeto de governo diferente do eleito pelo voto popular, principalmente pelas medidas contra a classe trabalhadora. O governo Temer fortalece as políticas neoliberais - que são justificadas como um grande plano de “modernização" do país -, visando à recuperação dos cofres públicos e ao crescimento econômico nacional através de ações que incentivam o capital internacional a investir internamente, ao mesmo tempo em que diminui a assistência e auxílio à população.

Até o momento, a reforma agrária e os recursos para a agricultura familiar sofreram grandes retrocessos. O legislativo federal eleito para o período de 2015-2018 conta com uma bancada 
ruralista que defende o agronegócio e se opõe às políticas de reforma agrária. O Programa de Aquisição de Alimento (PAA), que é uma das principais políticas públicas para o fortalecimento da agricultura familiar, sofreu um corte de $40 \%$ em seu orçamento, diminuindo o número de pessoas atendidas no combate à fome e o número de famílias agricultoras, que de 91,7 mil passou para 41,3 mil, ou seja, uma redução de 55\%. Outros programas que tiveram corte orçamentário anunciado ainda em 2016 foram os de reconhecimento das áreas quilombolas, com um corte de 48\% no orçamento e uma diminuição de 52\% dos cursos provenientes do Incra. A Secretaria Especial de Agricultura Familiar e do Desenvolvimento Agrário teve um corte de 37\% no orçamento em 2017 (MACEDO, 2017).

No plano orçamentário para 2018, a agricultura familiar sofreu ainda mais cortes: os 9,72 bilhões do orçamento de 2017 caem para 6,28 bilhões, o que significou uma diminuição de 34,5\%. Já a reforma agrária teve o orçamento reduzido em 28\% (MINISTÉRIO DO PLANEJAMENTO, 2017). Em 2016 foi votada a PEC 55, conhecida como a "PEC do teto dos gastos públicos", que prevê o corte de orçamento em despesas primárias, como saúde, educação, assistência, seguridade social, entre outras (DAVID; GOULARTI, 2016).

\section{Considerações finais}

Com a conquista do sufrágio universal e a reabertura do regime democrático no Brasil a questão dos camponeses e a luta pela reforma agrária não sofreu mudanças estruturais em comparação à sua conjuntura histórica. Os camponeses, principalmente no fim da década de 1980 , passaram a ter acesso aos direitos sociais, políticos e civis, momento esse que favoreceu a participação de muitos trabalhadores rurais em movimentos sociais e grupos organizados de luta por direitos e acesso à terra.

No entanto, durante os anos 1990, os governos democráticos não desenvolveram projetos amplos de reforma agrária. Uma das principais características dos governos da época foi a adoção do receituário neoliberal, o que resultou na diminuição dos recursos para políticas de intervenção na área da agricultura. Com a abertura comercial promovida pelo governo, houve o fim da política dos preços mínimos, dos estoques reguladores e dos créditos agrícolas, o que gerou uma queda de renda para os pequenos agricultores e, consequentemente, manteve a inviabilidade de acesso ao mercado para os camponeses pobres e sem recursos próprios. 
Nessa década também houve mudança no perfil das políticas públicas, principalmente no governo FHC, que focou em políticas assistencialistas localizadas e de caráter compensatório. A reforma agrária, no primeiro governo FHC, foi tratada de maneira a evitar conflitos, assentando muitas famílias que já estavam acampadas. No segundo governo propõe um modelo de "reforma agrária de mercado". Durante a década de 1990 houve negligência na área de políticas que permitissem condições dignas de produção agrícola por pequenos agricultores familiares e com recursos escassos. Com a abertura comercial e consequentemente a competição com os produtos agrícolas provenientes de países do Mercosul, os pequenos produtores sofreram grandes prejuízos.

No início dos anos 2000, o governo Lula, que contou com grande apoio dos movimentos de luta pela terra, desenvolveu um ambicioso plano de reforma agrária que não chegou a ser realizado em sua totalidade. Os governos petistas foram gestões que assumiram como principais metas a geração de empregos e o combate à fome e à pobreza. Desse modo, as políticas agrárias foram pensadas como mecanismos para garantir a segurança alimentar e o fim da fome, além de ser uma forma de garantia de renda mínima aos pequenos produtores. Dentre os programas, um dos mais importantes foi o Projeto de Aquisição de Alimentos, que visa à compra de produtos da categoria social, garantindo mercado e renda estável para os pequenos produtores. No entanto, não alcançaram as expectativas dos movimentos populares em relação à distribuição de terra, mas proporcionaram uma ampliação de políticas para as famílias já assentadas, com o aumento de recursos, promovendo melhorias em projetos destinados à construção de infraestrutura básica e a assistência técnica. Em síntese, a questão estrutural da propriedade da terra ficou em segundo plano, privilegiando a dimensão da produção para o consumo.

O governo Temer caminha na contramão dos governos que o antecederam, diminuindo de forma considerável os recursos destinados aos projetos de fortalecimento da agricultura familiar e criando algumas dificuldades para que os pequenos agricultores possam se vincular ao PAA. Desse modo, firma-se como um governo que rompe com os programas e políticas públicas dos governos Dilma e Lula.

Com a PEC 241, Temer se torna o principal avalista de um projeto de queda contínua de investimentos públicos nos próximos 20 anos nas áreas de políticas públicas de caráter social como a educação, saúde, segurança alimentar, segurança pública e funcionalismo público. Tudo isso caminha para a perpetuação do lugar subordinado dos camponeses, para a diminuição ou extinção de órgãos como o Incra, redução dos recursos para investimento em infraestrutura e financiamento 
para os pequenos produtores. Vislumbra-se, no caso dos camponeses e pequenos agricultores, um salto do século XXI para o XIX, reafirmando o fosso estrutural do campo brasileiro.

\section{Referências}

BELIK, W. et al. Políticas de combate à fome no Brasil. São Paulo em Perspectiva, p.119-129, 2001.

BRASIL. Decreto ${ }^{\circ}$ 53.700, de 13 de março de 1964. Diário Oficial da União: Seção 1.13 de mar. de 1964. Disponível em: <encurtador.com.br/bgtS5>. Acesso em: 30 out. 2018.

BRASIL. Medida Provisória $\mathrm{n}^{\circ}$ 2.109-52, de 24 de maio de 2001. Diário Oficial da União: Seção 1. 24 de maio de 2001. Disponível em: <encurtador.com.br/fjnu9>. Acesso em: 30 out. 2018.

BRASIL. Ministério do Planejamento, Desenvolvimento e Gestão. Secretaria de Orçamento Federal. Orçamento Cidadão: Projeto de Lei Orçamentária Anual - Ploa 2018. Brasília, 2017.

CARTER, M. Desigualdade social, democracia e reforma agrária no Brasil. In: CARTER, M. (Org.). Combatendo a desigualdade social: o MST e a reforma agrária no Brasil. São Paulo: Unesp, 2010. p. 27-80.

COELHO, F. Reforma agrária no governo FHC: perfil, tensões, número de famílias assentadas e áreas obtidas. Diálogos, v. 20, n. 2, p. 179-192, 2016.

CUNHA, J. Latifúndio, reforma agrária e políticas públicas para o campo brasileiro na crise sistêmica (1994-2015). Cadernos do CEAS, Salvador, n. 237, p. 196-224, 2016.

CUNHA FILHO, S. B. A Constituição de 1988 e a diminuição do poder estatal de desapropriar os imóveis rurais para fins de reforma agrária. 2007. Dissertação (Mestrado em Ciências Jurídicas) - Pontifícia Universidade Católica do Rio de Janeiro, Rio de Janeiro.

DAVID, G.; GOULARTI J. PEC 55: instrumento do $1 \%$ mais rico para ampliar desigualdades. Brasil Debate. 12 dez. 2016. Disponível em: <encurtador.com.br/vwyCL>. Acesso em: 25 fev. 2018.

DELGADO, G. A questão agrária e o agronegócio no Brasil. In: CARTER, M. (Org.). Combatendo a desigualdade social: o MST e a reforma agrária no Brasil. São Paulo: Unesp, 2010. p. 81-112.

DELGADO, N. O papel do rural no desenvolvimento nacional: da modernização conservadora dos anos 1970 ao governo Lula. In: DELGADO, N. (Org.). Brasil rural em debate. Brasília: Condraf/MDA, 2010. p. 28-77.

ESQUERDO, V.; BERGAMASCO S. Balanço sobre a reforma agrária brasileira nas duas últimas décadas. Interciência, p. 563-569, ago. 2013. 
FABRINI, J. A escala da luta e resistência camponesa. Geosul, Florianópolis, v. 21, n. 42, p. 63-91, jan. 2006.

FERNANDES, B. M. Questão agrária: conflitualidade e desenvolvimento territorial. In: BUAINAIN, A. M. (Org.). Luta pela terra, reforma agrária e gestão de conflitos no Brasil. Campinas: Editora da Unicamp, 2008. p. 173-224.

GRISA, C.; SCHNEIDER S. Três gerações de políticas públicas para a agricultura familiar e formas de interação entre sociedade e Estado no Brasil. Revista de Economia e Sociologia Rural, Brasília, v. 52, supl. 1, p. 125-146, 2014. Disponível em: <encurtador.com.br/lvx38>. Acesso em: 20 fev. 2018.

JANK, M. et al. Agronegócio e comércio exterior brasileiro. Revista USP, n. 64, p. 14-27, 1 fev. 2005.

MACEDO, E. Redução no PAA contribui para desmonte da agricultura familiar. Revista IHU, 02 ago. 2017. Disponível em: <encurtador.com.br/iopA1>. Acesso em: 10 fev. 2018.

MACIEL, D. Crise do neoliberalismo moderado e governo do PT. COLÓQUIO INTERNACIONAL MARX E O MARXISMO 2015: Insurreições, passado e presente, 2015. Universidade Federal Fluminense, Niterói, 24 a 28 de agosto de 2015.

MARTINS, J. Expropriação e violência: a questão política no campo. São Paulo: Hucitec, 1980.

MARTINS, J. Os camponeses e a política no Brasil: as lutas sociais no campo e seu lugar no processo político. Petrópolis: Vozes, 1981.

MEDEIROS, L. Movimentos sociais no campo, lutas por direitos e reforma agrária na segunda metade do século XX. In: CARTER, M. (Org.). Combatendo a desigualdade social: o MST e a reforma agrária no Brasil. São Paulo: Unesp, 2010. p. 113-136.

OLIVEIRA, A. A longa marcha do campesinato brasileiro: movimentos sociais, conflitos e reforma agrária. Estudos Avançados, v. 43, n. 15, p. 185-206, 2001.

PAULA, A. et al. Novo ciclo neoliberal no Brasil: desmontando as políticas públicas para a agricultura camponesa. Revista Pegada, p. 57-88, 2017.

QUEIROZ, A. Reforma da previdência: propaganda enganosa sobre aposentadoria rural. Disponível em:<encurtador.com.br/tuvF3>. Acesso em: 15 mar. 2018.

ROCHA, H. F. Análise e mapeamento da implantação de assentamentos rurais e da luta pela terra no Brasil entre 1985-2008. 2009. Monografia (Bacharelado em Geografia) - Unesp, Presidente Prudente.

TOLEDO, C. N. 1964: O golpe contra as reformas e a democracia. Rev. Bras. Hist, p. 13-28, 2004. 
WANDERLEY, M. Gênese da abordagem territorial no Brasil. In: WANDERLEY, M. et al. (Orgs.). Participação, território e cidadania: um olhar sobre a política de desenvolvimento territorial no Brasil, Recife: UFPE, 2014. p. 79-102.

WANDERLEY, M. Raízes históricas do campesinato brasileiro. XX ENCONTRO ANUAL DA ANPOCS, 1996, Caxambu - MG, outubro de 1996, p.1-18.

WELCH, C. et al. Introdução - Estudos clássicos brasileiros sobre o campesinato. In: WELCH C. et al. (Orgs.). Camponeses brasileiros: leituras e interpretações clássicas. São Paulo: Unesp, 2009.

Artigo recebido em 17/09/2018. Aceito para publicação em 08/12/2018. 